\title{
Imagens do Brasil, nos anos de 1955-1956, na visão do poeta surrealista e viajante francês Benjamin Péret
}

\author{
Images of Brazil, the years 1955-1956, \\ the vision of the traveler and French surrealist poet \\ Benjamin Péret
}

Robert Ponge*

\begin{abstract}
Resumo: O poeta surrealista francês Benjamin Péret morou duas vezes no Brasil: em 1929-1931 e em 1955-1956. Após um breve relato de sua agitada e multifacetada trajetória de vida (1899-1959), o presente trabalho objetiva dar uma ideia da imagem (e das imagens) que, em seus escritos, Benjamin Péret ofereceu do Brasil urbano durante parte de sua segunda permanência no Brasil. Baseado em sua correspondência (complementada, quando necessário, com outros documentos), este artigo concentra-se em dois aspectos: por um lado, sua visão do Rio de Janeiro (às vezes contrastada com suas lembranças de sua primeira estada, nos anos 19291931); por outro lado, suas anotações e comentários relativos à viagem que o levou às capitais do Norte e Nordeste. Encerra apresentando o balanço que o escritor francês fez de sua segunda estada brasileira.
\end{abstract}

Palavras-chave: Benjamin Péret. Brasil. Viagem.

Abstract: The French surrealist poet Benjamin Péret lived in Brazil twice: in 19291931 and in 1955-1956. After a brief account of his hectic multifaceted course of life (1899-1959), this paper aims at giving an idea of the image (and images) that, in his writings, Benjamin Péret provided of urban Brazil during part of his second stay in Brazil. Based on his correspondence (supplemented, when necessary, with other documents), this article focuses on two aspects: on one hand, his view of Rio de Janeiro (sometimes contrasted with his memories of his first stay in the years 1929-1931); on the other hand, his notes and comments concerning the trip that took him to the capital cities of the North and Northeast. The paper ends with a balance that the French writer made of his second stay in Brazil.

Keywords: Benjamin Péret. Brazil. Travel.

* Graduado e pós-graduado em Letras pela Universidade de Paris (França), doutor em Letras pela Universidade de São Paulo, professor titular aposentado da UFRGS, é, atualmente, professor convidado do Departamento de Línguas Modernas e do Programa de PósGraduação em Letras da mesma instituição. 
O poeta surrealista francês Benjamin Péret (1899-1959) viveu três vezes nas Américas: seis anos no México, de 1942 a 1948, e duas estadas no Brasil: inicialmente, de 1929 a 1931 (três anos) e, posteriormente, em 1955-1956 (quase onze meses), totalizando uma apreciável vivência de quatro anos no país verde-amarelo.

Durante seus dez anos em solo americano, Péret procurou entender cada um dos dois países em que morou: conhecer os habitantes e seus costumes, falar a língua vernacular, descobrir a geografia, fauna e flora, explorar as diversas regiões, examinar o campo e a cidade, as formas de habitação e de transporte, observar e analisar as crenças e os rituais religiosos, estudar o passado e o presente, compreender os processos históricos, políticos e sociais desde os tempos pré-colombianos até a época contemporânea. Durante seus anos americanos e depois, escreveu sobre o que viu e sobre o que estudou: em sua correspondência, em entrevistas e em artigos.

O presente trabalho objetiva dar uma ideia da imagem (e das imagens) que, em seus escritos, Benjamin Péret ofereceu do Brasil urbano durante parte de sua segunda estada brasileira. Baseado em sua correspondência (complementada, quando necessário, com outros documentos), este trabalho concentra-se em dois aspectos: por um lado, sua visão do Rio de Janeiro (às vezes contrastada com suas lembranças de sua primeira estada, nos anos 1929-1931); por outro lado, suas anotações e comentários relativos à viagem que o levou a Manaus e às capitais do Norte e Nordeste.

Antes, faz-se necessário apresentá-lo, iniciando com alguns elementos de informação relativos à sua trajetória de vida, situando na mesma o lugar da América Latina: o México e, particularmente, o Brasil.

\section{9-1959: trajetória de Péret, na França e alhures}

\section{França, 1899-1928}

Benjamin Péret nasce em 1899, no oeste da França, filho único de uma familha modesta. Em 1917, é obrigado a alistar-se na Primeira Guerra Mundial, da qual consegue sair são e salvo, porém extremamente revoltado.

Seus primeiros passos na poesia são de inspiração simbolista. A partir de 1918, descobre a poesia moderna através dos escritos de Guillaume Apollinaire (1880-1918), Arthur Rimbaud (1854-1891), Lautréamont (1846-1870) e Alfred Jarry (1873-1907); é uma autêntica revelação. Engaja-se então na busca de uma aventura poética e intelectual colocada 
sob o signo do não-conformismo: inicialmente, a partir de 1920, no dadaísmo; a partir de 1922 e para o resto de sua vida, no surrealismo. Em 1924-1925, junto com Pierre Naville, é incumbido da direção dos três primeiros números da revista La Révolution surréaliste (A Revolução Surrealista).

Em 1926, Péret adere ao Partido Comunista Francês - que abandona em 1928, decepcionado pela sua política e pelo seu funcionamento antidemocrático, burocrático. Daí em diante, passa a se identificar com a esquerda antistalinista de sensibilidade trotskista ${ }^{1}$.

No mesmo ano de 1928, Péret casa-se, em Paris, com a cantora lírica brasileira Elsie Houston (cunhada do jovem Mário Pedrosa), uma carioca que "possuía uma voz de timbre inesquecível, incluía em seu repertório peças modernas [...]" 2 e desenvolveu uma brilhante carreira internacional. No início de 1929, Elsie e Benjamin rumam para o Brasil.

\section{Brasil, 1929-1931}

O que leva Benjamin Péret ao Brasil? Sem dúvida, seu amor por Elsie e uma provável vontade desta de viver algum tempo em sua terra natal. Mas, também, o interesse de ambos pelas artes populares e primitivas deste país e da América Latina. Elsie tinha, com efeito, publicado, em Paris, um livro intitulado Chants populaires du Brésil (Cantos populares do Brasil) (Houston-Péret (1930). Quanto a Benjamin, junto com seus companheiros surrealistas, vê, nas artes populares e, sobretudo, primitivas, a essência do pensamento poético, do pensamento analógico.

A chegada de Elsie e Benjamin ao país, no início de fevereiro de 1929, recebe, inicialmente, uma boa cobertura da imprensa. Em entrevistas e artigos, Péret procura explicar o que é o surrealismo. Tece laços com a Revista de Antropofagia, que o saúda calorosamente e reproduz alguns de seus Provérbios atualizados para o gosto de hoje. Elsie e ele participam da famosa comitiva de antropófagos que acompanha Tarsila do Amaral ao Rio para sua exposição de julho de 1929.

Péret tenta empreender uma viagem no Norte e Nordeste do Brasil e entre os índios brasileiros; sem sucesso, por falta de dinheiro. Também, procura realizar um filme no qual o palhaço Piolim ficaria com o papel principal (novamente, sem sucesso e por ausência de suporte financeiro).

1 Sobre a atividade política de Péret, ver Prévan (1999).

2 Segundo o depoimento de Bento (1966, p. 67). 
Desenvolve dois estudos, no Rio: um sobre os cultos afro-brasileiros, que resulta numa série de treze artigos, intitulados "Candomblé e macumba" e publicados no Diário da Noite de São Paulo, de 25.11.1930 a 30.01.1931, trabalho cujo "pioneirismo" foi destacado pelo historiador Clovis Moura 3 ; o outro estudo versa sobre a Revolta da Chibata, ocorrida em 1910, para o qual pesquisa nos arquivos da Marinha ${ }^{4}$.

Em agosto de 1931, Elsie dá a luz a Geyser, seu filho. Em novembro, em função de seu envolvimento com o grupo trotskista brasileiro (dos quais são fundadores seus amigos Lívio Xavier, Fúlvio e Lélia Abramo, além de seu cunhado, Mário Pedrosa), é preso pela polícia política, provavelmente em função de uma denúncia. Na ocasião da prisão ou durante as buscas policiais decorrentes, o manuscrito do estudo sobre a Revolta da Chibata desaparece. No final de dezembro, após inquérito policial sumário, sem qualquer processo judicial e sem sequer direito a defesa, Benjamin Péret é expulso do país 5 .

\section{França, 1932-1941}

De volta à Paris, no início de 1932, Péret reencontra os amigos surrealistas (com os quais se manteve em contato durante sua estada brasileira) e consegue empregar-se como revisor, atividade profissional que será a sua até o final de sua vida.

Em agosto de 1934, Elsie e ele decidem separar-se (motivo: "sobretudo o fim do amor"'). Esta retorna ao Brasil, levando junto o filho, Geyser.

Em 1936-1937, da mesma forma que outros intelectuais (como André Malraux e George Orwell), transfere-se à Espanha para ajudar na luta contra o golpe de Estado franquista. Em Barcelona, conhece a pintora Remedios Varo, que se torna sua companheira. Em meados de 1937, volta para a França; Remedios o acompanha.

Em 1939, começa a Segunda Guerra Mundial. Péret é mobilizado. Após o colapso das tropas francesas diante daquelas do Terceiro Reich, refugia-se, com Remedios, em Marselha, onde solicita asilo no México.

3 Moura, Clovis. "Três vertentes de interesse de um poeta francês sobre o negro brasileiro". Conferência apresentada em 07.11.1985, na "Semana surrealista" organizada pela Aliança Francesa de São Paulo. Citado a partir do manuscrito dessa, (s.p.), ainda inédito, o qual me foi inicialmente comunicado por Jean Puyade: a ele meus agradecimentos.

4 Sobre a estada brasileira de Péret em 1929-1931, ver Puyade (2005, 13 p.). Disponível na rede no endereço <http://www.msmidia.com/conexao/>.

5 Sobre a atividade política de Péret no Brasil, ver Karepovs 1994, p. 217-234).

6 Péret (1995, p. 330). Nesta e nas demais citações originariamente em francês, a tradução para o português é minha, salvo indicação em contrário. 


\section{México, 1942-1947}

No início de janeiro de 1942, chega no México onde, durante seis anos, vive no exílio com Remedios, com quem casa, em 1943, após o falecimento de Elsie Houston.

Desenvolve intensa pesquisa sobre os povos pré-colombianos e começa a reunir textos de mitos, lendas e contos da América, com vistas à organização de uma antologia. Redige a primeira parte do texto de apresentação desta - um original estudo sobre as relações entre os mitos e a poesia, o qual é publicado por André Breton, em Nova Iorque (onde está exilado).

\section{França, 1948-1955, 1956-1959}

Volta à França no início de 1948 (Remedios fica no México). Trabalha como revisor. Como sempre fez, continua colaborando nas revistas e atividades do grupo surrealista. É na França que publica o que o México lhe ditou: em 1952, seu magnífico poema Ar mexicano; em 1955, sua excelente "Apresentação" e sua bela tradução, do espanhol para o francês, do Livro de Chilám Balám de Chumayel.

Seus problemas de saúde agravam-se, até sua hospitalização em 1954. Convalescência difícil. Seu filho convida-o para vir ao Brasil, para descansar, encontrá-lo, e - o mais importante para alguém que passou a vida inteira com constantes dificuldades materiais - manda o dinheiro para a passagem. Fica no Brasil de 7 de junho de 1955 a 18 de abril de 1956.

De volta à Paris, Péret permanece trabalhando como revisor. Consegue terminar sua Antologia do amor sublime e sua Antologia dos mitos, lendas e contos populares da América. Falece em 1959 de problemas cardíacos. ${ }^{7}$

Deixou atrás de si várias coletâneas de poesia, contos, ensaios e escritos de crítica. ${ }^{8}$ Em 1985, foi publicado no Brasil, em edição bilíngüe, um belo volume, Amor sublime, contendo uma seleção de poemas de Péret, um longo extrato de seu prefácio à Antologia do amor sublime, fotos dele, de Elsie Houston, depoimentos sobre eles.

7 Esta trajetória de Péret é uma versão reduzida daquela constante em: Ponge (2009, p. 237 242). Para maiores informações biográficas sobre Péret, ver: Bedouin (1961); Courtot (1965); Goutier (1982).

8 As obras completas de Péret foram publicadas pela Association des Amis de Benjamin Péret (AABP < http://www.benjamin-peret.org/>) em colaboração com a editora Éric Losfeld/Le Terrain vague (tomos 1 a 3) e, depois, com a editora José Corti (tomos 4 a 7). 


\section{A segunda estada brasileira: imagens do Rio de Janeiro}

No dia 24 de maio de 1955, Péret embarca no porto francês de Le Havre, com destino ao Brasil.

Quais são seus projetos? Além de rever seu filho e amigos, bem como descansar, pretende obter objetos ou fotos para sua coleção, ler sobre o Brasil, viajar a diversas regiões do país, terminar a redação de um ensaio e organizar dois livros.

Após uma travessia transatlântica "perfeita" ("tempo bom continuamente", p. $417^{9}$ ), desembarca no Rio de Janeiro em 7 de junho de 1955.

\section{No reencontro com o Rio, uma surpresa!}

Em sua correspondência, suas três primeiras apreciações são sobre o clima, o reencontro com seu filho (21 anos depois!) e a cidade. Elogia o filho (piloto da Varig) e o clima; o tom de suas observações muda radicalmente quando se refere à urbe: "Não reconheci nada da cidade, pois ela foi revirada de alto a baixo" (p.417).

Quinze dias depois, viaja a São Paulo. Sua reação é a mesma: “A mudança na cidade é incrível. Mais do que uma mudança, trata-se de uma metamorfose. Sequer conseguia encontrar a casa em que morava. A qual, por acaso, ainda está de pé" (p.418).

O que motiva a surpresa de Péret? Certamente, o contraste com a realidade urbana que conheceu em 1929-1931. Procuremos, então, conhecê-la, reconstituí-la, limitando-se, neste trabalho, à cidade do Rio de Janeiro.

O Rio em que Péret viveu, por ocasião de sua primeira estada brasileira e que deixou no final de 1931, era uma grande urbe, com uma população de cerca de um milhão e quatro centos mil habitantes. Já podia ser considerada moderna: possuía grandes avenidas, iluminação pública elétrica, linhas de bondes, novas construções. Apesar de ser predominantemente horizontal (sobretudo com casas particulares e prédios coletivos de dois a quatro e, às vezes, cinco ou seis andares), em seu centro já existiam prédios maiores do que oito andares e, mesmo, alguns arranha-céus. Nada, porém, que pudesse, então, surpreender

9 PÉRET. "Correspondance (1921-1959)". 1985. p. 417. A correspondência relativa à segunda estada brasileira de Péret encontra-se nas p. 416-445 do referido tomo 7 das Euvres complètes. Doravante, informarei diretamente no texto, entre parênteses, a(s) página(s) das citações extraídas da correspondência. 
um Péret procedente de Paris, cidade cujas ruas, desde o século 19, enfileiram-se entre dois paredões de fachadas de prédios de seis andares $^{10 .}$

A partir de 1932 (sobretudo no final dos anos trinta e ao longo dos anos quarenta e cinqüenta), enquanto Péret estava na França, abriu-se na vida do então Distrito Federal um novo período de crescimento e mudanças, com um acelerado aumento populacional, a proliferação das favelas, o crescimento da nova zona sul em torno de Copacabana, a aceleração do processo de verticalização dos prédios, uma febre de construção viária (avenidas, vias expressas, túneis) e a transformação da área central da cidade e adjacências (abertura de várias avenidas, com destaque para a av. Presidente Vargas, construção do aeroporto Santos Dumont e urbanização da esplanada do Castelo). Em meados dos anos 1950, quando Péret volta ao Brasil, a cidade possui cerca de dois milhões e oitocentos mil habitantes. ${ }^{11}$

\section{Uma cidade tomada pelos "cogumelos venenosos"}

Pode-se agora entender o choque levado por Benjamin Péret ao desembarcar, em 1955, num Rio de Janeiro em que a população duplicou: "A cidade mudou muito, tornou-se até irreconhecível". Imediatamente, acrescenta: "isso não constitui de forma alguma um progresso, muito pelo contrário". Por quê? Porque "os arranha-céus cresceram de maneira desordenada, feitos cogumelos venenosos" (p. 416). A imagem é significativa! $\mathrm{Na}$ correspondência do poeta francês, essa resposta e avaliação aparecem com outra formulação, menos metafórica mas não menos expressiva: a cidade encontra-se "extremamente norteamericanizad[a]" (p.427).

Isso é também verdade, e muito mais, relativamente a São Paulo. Porém, Péret observa que, diferentemente da urbe paulistana, "Rio ainda apresenta algum interesse", por causa de... seus jardins (p.427). Aliás, salienta ele, no Rio,

[...] há uma única coisa que permaneceu quase intacta: o Jardim Botânico, com a ressalva de que os esquilos pretos desapareceram. A não ser por isso - o que não é pouca coisa -, o Jardim Botânico continua maravilhoso e cheio de pássaros (p.416, grifo meu).

\footnotetext{
${ }^{10}$ Ver, entre outros: Abreu (1987, p. 71-91); Benchimol (1985, p. 599-611).

11 Ver, entre outros: Abreu (1987, p. 93-115); Rezende (1999, p. 44 ss)
} 
Grifei o inciso o que não é pouca coisa, pois remete a uma postura de Benjamin Péret: a mesma que adota diante de São Paulo ("uma cidade de arranha-céus", a qual "abriga vagas borboletas que vagueiam melancolicamente de uma parede de concreto à outra [...]", p.421). Com o desaparecimento dos esquilos no Rio de Janeiro e com a rara presença de melancólicas borboletas em São Paulo - dois fatos justapostos à multiplicação dos arranha-céus (ou seja, a floresta de concreto que acaba com os bosques e jardins) -, Péret sugere, aponta dois dos medidores com os quais ele avalia a habitabilidade das cidades:

- uma cidade à escala do ser humano, em que o homem não seja esmagado pela altura e pela quantidade de arranha-céus (isto é, pelo adensamento de sua presença);

- uma cidade em que haja a preservação da natureza enquanto meio vegetal e animal no qual, ao lado do qual e com o qual vive/convive o homem. Ou seja, uma cidade em que a natureza possa viver, como relembra oportunamente Péret, em outra correspondência, a respeito de um bairro: "Neste lugar, outrora [isto é, em 1929-1931], havia preguiças. Desapareceram, provavelmente mortas pelos gases dos automóveis." (p. 420).

Isso, numa época em que a ecologia não se tornara ainda uma reivindicação premente!

Péret não era avesso ao progresso, ao moderno. Mas, há moderno e moderno: ele não poderia ser ufanista, modista; não poderia enxergar carinhosamente o Rio de Janeiro sem um olhar atento, rigoroso - um olhar crítico, justamente porque carinhoso!

\section{A "loucura" da febre modernizante}

Basta-lhe uma curtíssima frase (extraída de carta a uma amiga francesa) - "Aqui, a loucura reina" - para dar sua opinião a respeito da febre modernizante que tomou conta do Brasil, inclusive e particularmente do Rio (estamos às vésperas do período Cinquenta anos em cinco! de Juscelino Kubitschek, que está em plena campanha eleitoral quando Péret desembarca no Brasil).

Mas, por que reina a loucura? Continuo citando a mesma carta:

[...] nesse país, do qual os três quartos, se não for mais, são inabitados, eles passam seu tempo conquistando do mar alguns miseráveis metros de terra firme, gastando somas fabulosas, quando o deserto [entenda-se: áreas com baixa densidade populacional] começa a poucos quilômetros de lá, assim que se deixa o litoral. (p. 416) 
A referência é, obviamente, ao aterramento para a via expressa ligando Copacabana ao centro do Rio, mas ela tem valor geral, remetendo às somas fabulosas gastas para outros aterros ou túneis ou seja lá o que for.

No caso, tratava-se de adequar a cidade maravilhosa (e, para tanto, submetê-la) às imperiosas necessidades de um meio de transporte individual e particular - o carro -, cuja vertiginosa multiplicação estava sendo incentivada, em detrimento, por exemplo, de um então inexistente - e hoje ainda raquítico - meio de transporte coletivo: o metrô!

De forma que, sem querer, as observações de Benjamin Péret sobre o Rio de Janeiro dos anos 1950 ainda possuem algum grau de atualidade. O que não deixa de ser um convite à reflexão!

\section{A segunda estada: o interior de São Paulo, o Norte e o Nordeste}

Essas são as primeiras impressões e imagens de Benjamin Péret sobre o Rio. O que mais ele pensa e faz a seguir?

Esforça-se em obter, das mais diversas fontes, borboletas (que adora colecionar), bem como objetos e/ou fotos de objetos de arte brasileira indígena e popular. Procura documentar-se sobre o país; um amigo brasileiro lembrará "a febre que o possuía de ler tudo que tratasse do Brasil". As obras sobre o quilombo dos Palmares "solicita[vam] em especial seu interesse" 12 , pois tenciona produzir um ensaio sobre o assunto. Além deste, está projetando dois outros livros: um de fotos de peças de arte primitiva, pré-colombiana e popular do Brasil; outro, bem mais volumoso (150 a 200 páginas), no qual desenvolveria seus trabalhos de etnografia já publicados em 1950-1952.

Em agosto, viaja pelo interior paulista e passa quinze dias numa fazenda cafeeira do oeste do estado, onde escreve a segunda parte da "Introdução" à Antologia dos mitos, lendas e contos populares da América que vem organizando desde o México ${ }^{13}$; trabalha, ainda, à redação do texto sobre Palmares, que consegue terminar durante a primeira quinzena de setembro.

${ }^{12}$ COELHO, Ruy. "Prefácio" a: PÉRET. O quilombo de Palmares. Lisboa: Fenda Edições, 1988. p. 11.

13 A primeira parte desta introdução havia sido finalizada em novembro de 1942, no México; fora publicada por Breton, em Nova Iorque (onde estava exilado), em 1943, sob o título A palavra está com Péret. 
Volta-se então para seus dois projetos de livros (não alcançará, porém, terminar e editá-los) e para suas viagens no resto do país, que são várias vezes adiadas (em particular para participar do casamento de seu filho)

\section{Manaus, as capitais do Norte e do Nordeste}

Finalmente, em 5 de outubro, Benjamin Péret inicia uma viagem na Amazônia, Norte e Nordeste. Os aviões da FAB ou do CAN (Correio Aéreo Nacional) o levam de capital em capital, ficando uns 4, 5 ou 7 dias em cada uma; às vezes, explora alguns recantos do interior profundo.

O roteiro o conduz inicialmente a Manaus: é uma decepção, a cidade não lhe agrada nem um pouco ("Impossível encontrar algo interessante. [...]. E quanta miséria!"). Depois, alcança Belém (a cidade é "mais simpática e um pouco menos quente", p.431). Segue para São Luís, Fortaleza e, no interior do Ceará, Granja. Chega a Recife, onde fica uma semana e dá uma entrevista ao Diário de Pernambuco. Finalmente, Salvador, a cidade "mais estranha" (p. 418) que viu em sua viagem (talvez por ser "uma espécie de Roma negra" (Péret, 1992, p. 73)).

De Salvador, Péret volta a São Paulo e ao Rio, onde chega em torno do 25 de novembro, após percorrer cerca de nove mil quilômetros em aviões a hélice. O périplo durou um pouco mais de sete semanas. Quais são as lembranças que se sobressaem do mesmo, quais imagens marcantes ele traz de volta? Antes de mais nada, a miséria: “[...] a miséria é fantástica no Norte. Em Manaus, mais da metade da população vive em condições infra-humanas." (p.433)

A declaração não vale apenas para Manaus, mas para todo o Norte e Nordeste dominados pela carestia, insalubridade, disenteria, sífilis, analfabetismo, etc. Para não deixar margem à dúvida, ele comenta: "Em suma, é apenas nas grandes cidade que os trabalhadores tem uma vida mais ou menos suportável [...]" (p. 433).

Nas grandes cidades? Não em Manaus, nem em suas similares, mas no Rio, em São Paulo (e, talvez, em algumas outras), cidades em que "a mudança mais notável está no nível de vida das pessoas que se vêem na rua. Enquanto 25 anos atrás a população nunca andava inteiramente vestida e trajava farrapos, ela agora se veste razoavelmente." (p. 418).

E por que essa diferença? "[...] devido [...] ao considerável desenvolvimento da indústria", o que, segundo ele, "representa uma mudança fantástica" (p.418).

Seria Péret ufanista em relação às grandes cidades, ditas modernas? De forma alguma; observemos que ele fala em pessoas vestidas 
razoavelmente e em vida mais ou menos suportável! E, novamente para não deixar dúvida nenhuma, ele imediatamente acrescenta uma precisão fundamental: esse nível de vida mais ou menos suportável dos trabalhadores das grandes cidades "não chega perto daquele dos trabalhadores dos países mais atrasados da Europa", mas ele reconhece que deve obviamente ser descontado um fato: no Brasil, "as necessidades imediatas são menores" do que na Europa (p. 433).

\section{Final da segunda estada brasileira}

Péret fica no Rio até 26 de janeiro de 1956 quando embarca num avião da FAB com destino ao Mato Grosso. Visita uma aldeia de índios xavantes, em Xavantina (hoje Nova Xavantina). Volta ao Rio.

Pelo 10 de fevereiro, viaja de novo ao Mato Grosso, visitando inicialmente uma aldeia de índios karajás, na ponta norte da ilha de Bananal, a seguir o posto Capitão Vasconcelos (hoje posto Leonardo Villas Boas) instalado pelo Serviço de Proteção ao Índios (SPI) à beira do rio Kuluene, no Alto Xingú (hoje Parque Indígena do Xingú). Prevista para dez dias, essa segunda viagem entre os índios acaba durando um mês.

Em 18 de abril, embarca no navio que o leva de volta à terra natal, onde chega em 3 de maio. ${ }^{14}$

\section{Balanços}

Qual balanço Péret faz de sua segunda estada brasileira?

A viagem a Manaus, ao Norte e Nordeste foi decepcionante "no tocante aos achados"; comenta com uma pitada de humor: "Nenhum objeto selvagem, como se todos os índios do Brasil só vestissem fraque, viajassem de Cadillac e morassem em arranha-céus com um refrigerador à mão!" (p. 440).

Mesmo assim, o balanço é globalmente positivo: "Fiz uma excelente viagem" (p. 430). Por que excelente? Porque conseguiu "muitas fotos de arte pré-colombiana, primitiva e popular" (p.434), porque observou bastante.

\footnotetext{
${ }^{14}$ Sobre os últimos meses da segunda estada de Péret no Brasil e suas duas viagens ao Mato Grosso, ver: PONGE, Robert. "Des anthropophages de São Paulo aux indiens kalapálos qui ont 'mangé l'explorateur Fawcett': les séjours brésiliens de Benjamin Péret”. Trois Cerises et une sardine, $\mathrm{n}^{\circ}$ 17. Paris: Association des amis de Benjamin Péret, oct. 2005. p. 6-8.
} 
O balanço não é menos positivo relativamente ao conjunto da estada de dez meses e meio: "Minha viagem ao Brasil foi muito frutífera". Com efeito, Péret teve a imensa satisfação de realizar vários dos projetos que o tinham motivado a vir ao Brasil em 1929 ("Conheci todo o norte do país até a Amazônia e fiquei um mês entre os índios do Brasil central [...]", p.455). Sobretudo, me parece, porque viu e aprendeu em abundância. São testemunho e prova disso sua correspondência, as várias entrevistas que deu no Brasil e na França, a mina de material (principalmente fotográfico) que reuniu para o livro sobre as artes primitivas e populares do Brasil (material que continua inédito até hoje), bem como os textos sobre o Brasil redigidos durante sua viagem e após sua volta, entre os quais o importante ensaio interpretativo sobre o quilombo de Palmares (publicado nos números 65 e 66 - abril e maio de 1956 - da Anhembi, uma importante revista cultural paulista da época ${ }^{15}$ ) e cinco artigos sobre os indígenas do Brasil (publicados: um na Manchete, outro na Anhembi, os demais em revistas francesas $\left.{ }^{16}\right)$.

\section{Referências}

ABREU, Maurício de A. Evolução urbana do Rio de Janeiro. Rio de Janeiro: IPLANRIO (Instituto de Planejamento Municipal do Rio de Janeiro)/Zahar, 1987.

BEDOUIN, Jean-Louis. Benjamin Péret. Paris: Seghers, coll. "Poètes d'aujourd'hui", 1961.

BENCHIMOL, Jaime Larry. A modernização do Rio de Janeiro. In: DEL BRENNA, Giovanna Rosso (Org.). O Rio de Janeiro de Pereira Passos: uma cidade em questão II. Rio de Janeiro: Index, 1985. p. 599-611.

BENTO, Antônio. O ambiente no Rio ao tempo de Ismael Nery. Cadernos Brasileiros, Rio de Janeiro, ano VIII, v. 35, n. 3, p. 61-69. maio/jun. 1966.

COELHO, Ruy. Prefácio a: PÉRET. O quilombo de Palmares. Lisboa: Fenda Edições, 1988. p. 9-12.

COURTOT, Claude. Introduction à la lecture de Benjamin Péret. Paris: Le Terrain vague/Association des amis de Benjamin Péret, 1965.

GOUTIER, Jean-Michel (Dir.). Benjamin Péret. Paris: Henri Veyrier, 1982.

HOUSTON-PÉRET, Elsie. Chants populaires du Brésil, première série recueillie et publiée par Mme Elsie Houston-Péret. Introduction par Philippe Stern. Paris: Librairie orientaliste Paul Geuthner, "Bibliothèque musicale du Musée de la parole et du musée Guimet", 1930.

KAREPOVS. "Benjamin Péret: surrealismo e trotskismo no Brasil". In: COGGIOLA, Osvaldo (Org.). Trotsky hoje. São Paulo: Editora Ensaio, "Cadernos Ensaio, série Grande Formato", 1994. p. 217-234.

\footnotetext{
${ }_{15}$ O quilombo dos Palmares de Péret foi republicado, em formato de livro, em 1988, em Portugal (Lisboa: Fenda Edições) e em 2002, no Brasil (Porto Alegre: Editora da UFRGS).

16 Podem ser encontrados em: PÉRET. CEuvres complètes, tome 6. Op. cit. p. 117-164.
} 
MOURA, Clovis. Três vertentes de interesse de um poeta francês sobre o negro brasileiro. Conferência apresentada em 07 nov. 1985, na SEMANA SURREALISTA, organizada pela Aliança Francesa de São Paulo. s.p.

PÉRET. Amor sublime: ensaio e poesia. Organizado por Jean Puyade. Textos traduzidos do francês por Sérgio Lima e Pierre Clemens. São Paulo: Brasiliense, 1985.

PÉRET, Benjamin. Euvres complètes. Paris: José Corti/Association des amis de Benjamin Péret, 1992. Tome 6.

PÉRET, Benjamin. Euvres complètes. Paris: José Corti/Association des amis de Benjamin Péret, 1995. Tome 7.

PÉRET, Benjamin. O quilombo dos Palmares. Organização, ensaios e comentários por Robert Ponge e Mário Maestri. Porto Alegre: Editora da UFRGS, 2002.

PONGE, Robert. Des anthropophages de São Paulo aux indiens kalapálos qui ont "mangé l'explorateur Fawcett": les séjours brésiliens de Benjamin Péret. Trois Cerises et une sardine, Paris: Association des amis de Benjamin Péret, n. 17, p. 2-15, Oct. 2005.

PRÉVAN, Guy. Benjamin Péret. Paris: Syllepse, coll. “Archipels du surréalisme”, 1999.

PUYADE, Jean. "Benjamin Péret: um surrealista no Brasil". Revista Conexão-Letras, Porto Alegre: Programa de Pós-Graduação em Letras, n. 1, 13 p., oct. 2005. Disponível em: <http://www.msmidia.com/conexao/>.

REZENDE, Vera F. "Evolução da produção urbanística na cidade do Rio de Janeiro: 1900-1950-1965. In: LEME, Maria Cristina da Silva (Org.). Urbanismo no Brasil: 18951965. São Paulo: FAU e FUPAM da USP/Studio Nobel, 1999. p. 39-70. 
